\title{
Southeast Raleigh Minority Faith-based Health Promotion Project
}

\author{
Nicolette Warren ${ }^{1}$, Patricia Moorman², Morris J. Dunn ${ }^{3}$, Carol S. Mitchell ${ }^{3}$, \\ Ariel Fisher ${ }^{4}, \&$ Myron F. Floyd ${ }^{5}$ \\ ${ }^{1}$ Society for Public Health Education \\ ${ }^{2}$ Department of Community and Family Medicine, Duke University Medical Center \\ ${ }^{3}$ NC Cooperative Extension, Wake County Center \\ ${ }^{4}$ Gethsemane Seventh-day Adventist Church \\ ${ }^{5}$ North Carolina State University
}

\begin{abstract}
Faith-based organizations are a powerful resource for addressing health issues within the African American community. In this paper, we describe two projects led by volunteer faith-based leaders and community residents who collaborated with public agencies to design programs to combat obesity. The first project, the Southeast Raleigh Community Garden Project, involved the construction of a community garden and the delivery of educational programs on healthy eating among youth. The second one, Project FACT (Faith-based groups Addressing health issues through Community outreach Together in the community), implemented church-based nutrition education programs and community walking programs led by church volunteers. The purpose of the two faith-based health promotion projects was to increase opportunities for physical activity and to encourage consumption of more fruits and vegetables. These projects resulted in the construction of a walking trail with the community garden as its destination, implementation of education programs to increase nutritional awareness, the initiation of multiple walking programs, and policy changes within the church to encourage a healthier lifestyle. The projects demonstrated the feasibility of collaboration among faith-based organizations, community residents and government agencies to promote physical activity and healthful eating among families by creating physical changes in the environment and implementing educational and walking programs in low income communities.
\end{abstract}

(c) 2009 Californian Journal of Health Promotion. All rights reserved.

Keywords: African Americans, faith-based partnership, community training, youth, community garden, physical activity, walking programs, fresh products, nutrition

\section{Introduction}

Faith-based organizations can play a key role in community-based health promotion and prevention programs among African Americans. Churches make important contributions to these health promotion efforts because of their central role in spiritual guidance, communication, social support and networking (Carleton \& Elder, 1986; Kumanyika \& Charleston, 1992; Lasater, Becker, Hill \& Gans, 1997; Lasater, Wells, Carleton \& Elder,1996; Olson, Reis, Murphy \& Gehm, 1988). Faith-based organizations offer their members an opportunity to improve their health habits, from an emotional and spiritual perspective, as well as an organizational perspective (Physical Activity and Nutrition Branch, 2004). They are concerned about individual member's well-being, have programs and services that support their members, are focal points for their communities, and their leaders are widely respected (Physical Activity and Nutrition Branch, 2004). We describe in this paper a volunteer faith-based community-driven outreach partnership among community organizations and public agencies designed to increase physical activity and improve nutrition among African-American youth and adults. 


\section{Background}

African Americans are at high risk for and have increased mortality from many medical conditions associated with overweight and obesity, including high blood pressure, diabetes, heart disease, stroke and cancer (Resincow et al., 2004). The epidemic of obesity in the United States is a major public health crisis that affects all race and ethnic groups, but African Americans are disproportionately affected (Ogden et al., 2006). The Centers for Disease Control and Prevention (CDC) estimates that in 2006-2008, the age-adjusted prevalence of obesity among non-Hispanic Blacks was $35.7 \%$ compared to $23.7 \%$ among non-Hispanic Whites (Pan et al., 2009).

Obesity often manifests itself during childhood, leading to a number of adverse health conditions across the lifespan. Diseases that are often thought of as adult health problems including high blood pressure, high cholesterol, and Type 2 diabetes are much more common among obese children and adolescents than among those who are not overweight (Freedman, Mei, Srinivasan, Berenson \& Dietz, 2007). Furthermore, overweight children and adolescents are more likely to become obese adults (Whitaker, Wright, Pepe, Seidel \& Dietz, 1997; Serdula, Ivey, Coates, \& Freedman, 1993).

Physical inactivity and poor dietary patterns are some of the primary determinants of obesity and have substantial effects on many chronic diseases (Crespo, 2005). Participation in regular physical activity is associated with a reduced risk of developing as well as improvement in symptoms of chronic diseases (US Dept of Health \& Human Services, 1996). Despite the known benefits of physical activity, most adults in the United States do not obtain adequate physical activity, and the level of activity is lower among racial/ethnic minorities as compared to non-Hispanic Whites (Crespo, 2005). Therefore strategies are needed particularly among African Americans to successfully create immediate and sustained behavior change related to physical activity (Whitt-Glover, Hogan, Lang, \& Heil, 2008).
Qualitative studies that examine perceived influences on physical activity participation provide useful information for understanding the attitudes and experiences with exercise among African Americans (Bopp et al., 2007). Barriers to participating in physical activity include factors both at the individual level (time constraints and competing responsibilities) and at the environmental level (availability of facilities and safety concerns). The particularly low rates of physical activity in African Americans and low-income adults may be influenced by characteristics of the built environment, including access to physical activity resources and greater street connectivity (Heinrich et al, 2007). Adherence to a walking intervention has been shown to be affected by environmental variables (Zenk et al., 2009). The overall evidence suggests that physical activity interventions that seek to reduce obesity among African Americans must target both the individual and the environment.

In addition to having sub-optimal physical activity levels, African Americans and individuals of lower socioeconomic status also tend to have dietary habits that contribute to risk of chronic disease, including higher intake of fat and lower intake of fruits and vegetables (Crespo, 2005). Gardening is one strategy to improve health and wellness in low resource areas that addresses both unhealthy dietary habits and physical inactivity. The potential benefits of gardening are numerous. Most importantly, gardens can provide an inexpensive, readily available source of fresh fruits and vegetables. Gardening is also an excellent way to engage in physical activity and may be a source of personal satisfaction and pride providing aesthetic pleasure and opportunity for relief from daily stress (Davies, 1998).

Gardens may have particular value for children, as they serve as hands-on-learning laboratories, which may make children much more willing to try and consume fresh fruits and vegetables that they have grown (Klick, 2009). In fact, children are more likely to try things they never have 
eaten before because they have tended the plants through harvest (Klick, 2009). Community gardens represent an option for addressing both the nutritional and physical activity components of obesity while providing added benefits to the community. According to the National Gardening Association, community gardens provide a source of food, add aesthetic value, encourage physical activity, help preserve cultural identity and, most importantly, cultivate neighborhood relationships (National Gardening Association, 2009).

The church setting may be ideal for initiating a community garden and related activities to improve nutrition and participation in physical activity. Faith-based initiatives have been used successfully to address a number of healthrelated risk factors and behaviors including smoking cessation (Voorhees et al., 1996), improving cardiovascular disease risk factors (Oexmann et al., 2000; Wiist \& Flack, 1990; Smith, Merritt, \& Patel, 1997) and increasing fruit and vegetable consumption (Campbell et al. 1999; Campbell et al. 2000; Resnicow et al., 2002). Several faith-based initiatives have included physical activity within their programs focusing on other outcomes (Kumanyika \& Charleston, 1992; Doshi et al., 1994; Yanek, Becker, Moy, Gittelson, \& Koffman, 2001). Although there have been a number of programs within faith-based communities to address nutrition and physical activity, we are unaware of any published reports that have described volunteer faith-based leaders and community residents securing grant funds to construct a community garden within a church community as a method to promote physical activity and greater fruit and vegetable consumption.

In this paper, we report on two inter-related health promotion projects led by volunteers from a faith-based community that were designed to target obesity by addressing the poor eating habits and lack of physical activity among African American youth and adults. Members of the church formed community partnerships centered on a community garden, walking programs and educational programs designed to increase physical activity and improve nutrition among African American youth and adults. We describe in this report the strategies used within each project to encourage better nutritional habits and create opportunities for exercise. We discuss the implementation of the projects and the outcomes observed among members of the congregation and the surrounding community.

\section{Description of Faith-Based Health Promotion Projects}

The faith-based health promotion projects were led by volunteers at Gethsemane Seventh-day Adventist (SDA) Church, a predominantly African American inner city congregation in Raleigh, North Carolina. There were two related projects: the Southeast Raleigh Community Garden Project and Project FACT (Faith-based groups Addressing health issues through Community outreach Together in the community). The community garden was created in 2005 and continued through 2007, and Project FACT was implemented between 2007 and 2009.

The overall purpose of the faith-based health promotion projects was: 1) to reduce the proportion of youth and adults who engage in no leisure-time physical activity and 2) to increase the number of youth and adults who eat at least five servings of fruits and vegetables per day. Each of the projects worked towards improving nutrition and increasing opportunities for physical activity through a number of interrelated objectives.

The objectives of the Southeast Raleigh Community Garden project were:

1. To establish a community garden through a collaboration of church leaders and congregation and community members.

2. To conduct nutrition education programs for children in the church school and day care center.

3. To encourage healthier eating through policy changes at the church, school and day care center.

The objectives of Project FACT were to:

1. To conduct educational programs on healthy eating for families. 
2. To increase opportunities for physical activity through construction of a walking trail and the establishment of walking programs.

\section{Southeast Raleigh Community Garden Project}

The Southeast Raleigh Community Garden pilot project was implemented in 2005 - 2007 with the goals of improving eating habits in children aged 4-13 and their families, increasing physical activity, and building a sense of community. The community gardening project was developed under the direction of the local North Carolina Cooperative Extension-Wake County Center and included other community partners such as the North Carolina Department of Agriculture, Soil and Water Conservation Services, North Carolina Coalition of Farm and Rural Families, the City of Raleigh and church leaders, residents and volunteers.

A total of 276 individuals were involved in the pilot project, which included 150 adults and 126 children and youth from the church school, the child care center, the community outreach program (Pathfinders) and the surrounding community. The participants were recruited through Saturday morning worship service announcements, church bulletin inserts, weekly church activities and flyers placed throughout the church, school and community.

\section{The Community Garden}

The Southeast Raleigh Community Garden was located on 0.2 acres of property owned by the church. The community garden consisted of thirty planting rows which were available to individuals, families and groups to grow food, flowers and herbs. Some of the rows in the garden plot were allocated especially for children. Children ages 4-9 years were paired with children aged 10-13 years in the gardening process. Table 1 shows the produce generated from the garden, with more than 8,000 servings of fruits and vegetables harvested. The number of servings was computed based on the weight of the different types of harvested produce using formulas provided by the North Carolina Cooperative Extension shown in Table 1. The garden also provided opportunities for physical activity among participating children and adults.
During a one-month monitoring period, it was determined that the average amount of time worked in the garden was 12 hours among adult participants and 4.5 hours among the youth. The monitoring was completed by direct observation by school and Cooperation Extension personnel, parents and other participating adults.

Table 1

Amount of fruits and vegetables produced from the community garden.

\begin{tabular}{lc}
\hline $\begin{array}{l}\text { Vegetables } \\
\text { Produced }\end{array}$ & Number of Servings \\
\hline Tomatoes & 3,932 \\
Squash & 1,588 \\
Cucumbers & 680 \\
Cantaloupes & 678 \\
Watermelons & 816 \\
Field Peas & 314 \\
Sweet Peppers & 222 \\
& \\
TOTALS & $\mathbf{8 , 2 3 0}$ \\
\hline
\end{tabular}

Formula used to estimate number of servings produced:

1. Used $1 / 2$ cup which equal 4 ounces.

2. Find the total pounds for each vegetable and multiply by 16 ounces which is one pound.

Example: 100 pounds of tomatoes X 16 Ounces $=1,600$ total ounces. 1,600 total ounces divided by 4 Ounces $(1 / 2$ cup) $=400$ Servings

\section{Youth Educational Component}

Educational sessions were incorporated into the community garden project. The North Carolina Cooperative Extension-Wake County Center provided educational/training sessions that addressed the 2005 Dietary Guidelines and My Pyramid. The educational programs were interactive activities designed to increase the consumption of fruits and vegetables among the participating children. The children were taught the benefits of eating healthy and being active through a variety of educational programs including Color Me Healthy (Dunn, Thomas, Pegram, Ward \& Schmal, 2004), Down to Earth (North Carolina A\&T State University Cooperative Extension Program, 2009), Garden Mosaics (2009), and 5 A Day (CDC, 2009). Attendance at the weekly educational training sessions averaged 22 children.

As part of each of the educational sessions, children were introduced to a variety of fruits 
and vegetables and were encouraged to eat at least one full serving of some type of fresh produce. Parents, school and child care staff, Cooperative Extension personnel and adult volunteers were asked to observe the children during the fresh produce tasting activities and events to confirm that the children tried each type of fruit and vegetable served at the activity. The educational sessions were followed by grocery store tours, in which the children were able to demonstrate recognition and retention of knowledge about fruits and vegetables. There was no funding to conduct formal evaluation of the educational sessions, but based on observations during the activities, the children appeared to connect with the gardening experience. Furthermore, in interviews captured on DVDs created by the North Carolina Cooperative Extension, parents reported that their children increased their physical activity and consumed more fresh fruits and vegetables.

\section{Policy Changes and Outreach}

The output of the garden was distributed through a variety of mechanisms that extended beyond the children and adults who worked in the garden. The organizers of the community garden partnered with the leaders of the church to encourage the development of policies to serve healthier foods during church activities and in the church school and child care center. For example, the child care center established a policy to provide $100 \%$ juice or low fat milk while providing at least five servings of fruits and vegetables each day. In addition, the Community Service Department of the church operated a food assistance outreach service program for community residents sponsored by the Food Bank of Central and Eastern North Carolina. According to the monthly reports submitted to the Food Bank, the church Community Service Department distributed fresh fruits and vegetables to over 200 lowincome community residents weekly. Fresh products from the garden were also incorporated into church sponsored events such as weekly lunches served after church services. These policies were communicated through announcements during church services, in bulletin announcements, and in flyers distributed in the church and surrounding community.
A secondary outcome of the community garden was its entrepreneurial component. The 126 children and 150 adults who participated in the garden were encouraged to sell the surplus produce at the local farmer's market or flea market. The youth also marketed and sold the fresh produce at nominal cost at roadside stands in the community. For example, once a quarter on a Sunday early afternoon, the youth created and displayed signs advertising the roadside stand sales at the church. In addition, on Wednesday nights, fresh produce was sold to church and community members at the church. Thus, the benefits of the garden were extended to members of the community who were not members of the church.

\section{Project FACT}

The second project implemented by volunteers from the Gethsemane SDA church was Project FACT, an educational and health promotion program that was undertaken as a complement to the community garden. The Project FACT partnership consisted of eleven agencies, nine churches, four community service groups and two ministerial alliances in Wake County, North Carolina that sponsored events that promoted healthy active neighborhoods and communities. Project FACT was initially started in Lee County in Sanford, North Carolina in 2002 by staff at Lee County Health Department and later expanded to Wake County in Raleigh, North Carolina in 2007 under the leadership of the Gethsemane SDA Church. The church partnered with the North Carolina Cooperation ExtensionWake County Center, City of Raleigh, Parks and Recreation, North Carolina State University and Wake County Human Services to provide community-based education including lay health ministry advisors training, and physical activity opportunities such as walking programs and other fitness related activities.

\section{Nutrition Education Program}

The educational component of Project FACT was conducted in collaboration with the Cancer Information Service, Southeast region located at Duke University Comprehensive Cancer Center. It utilized a National Cancer Institute Health promotion program called Body \& Soul, which was designed specifically to be implemented in 
African American churches (Resnicow et al., 2004). The Body \& Soul program encourages church members to eat a diet rich in fruits and vegetables as part of a healthy lifestyle. The Body \& Soul uses four major pillars or components that represent the core implementation structure of the program at the church level:

1. Committed and involved pastoral support

2. Church activities that promote healthy eating

3. Creating a church environment that promotes healthy eating

4. Peer counselors to motivate church members

The Body \& Soul program is based on the ecologic model and incorporates lay health advisors, church committees, community coalitions and events, educational sessions and pastor involvement that can lead to environmental changes aimed at increasing availability of fruits and vegetables at church functions (Resnicow et al., 2004). The two Body \& Soul sessions provided training for seven African American churches and ten local agencies in the Southeast Raleigh, North Carolina community. Four of the seven churches trained in the Body \& Soul program collaborated to implement Body \& Soul program activities.

\section{Walking Trail and Walking Programs}

Another component of Project FACT was the construction of a walking trail with the community garden at Gethsemane SDA Church as a center of attraction. The church trail was one of two community walking trails utilized in walking programs which were started among the partner churches. The walking programs included Southeast Raleigh on the Move, Eight Weeks to Wellness (2009), Fitness For Life (2009), 21 Days Fitness Challenge and two annual community walks. The different walking programs were led by church volunteers, and residents of the surrounding communities were welcomed and encouraged to participate. Seven churches participated in the Southeast Raleigh on the Move walking program with over 70 participants. Two churches implemented the Eight Weeks to Wellness program and another implemented the 10 week Fitness For Life program. Wake County Human Services coordinated the 21 Days Fitness Challenge and two annual community walks in collaboration with Southeast Raleigh Health Matters, a group of six churches. Gethsemane SDA Church members also initiated and submitted a petition to the City of Raleigh to build a sidewalk to connect the church property and community garden to a nearby park and surrounding neighborhoods. The petition has been approved by the City of Raleigh and the sidewalk will be constructed by the Public Works Department in 2010. Since the approval of the sidewalk construction, Gethsemane SDA Church completed the construction of a playground on the church property for the community.

As a result of Project FACT and the Body \& Soul training, nine churches signed a health policy agreement to provide a menu of opportunities for healthy lifestyle activities among their congregations such as serving heart healthy food options and incorporating physical activity into church events. Six of the nine churches that signed the health policy agreements collaborated to plan two annual community events. These events, which included a one-mile walk and served only heart healthy food options, were attended by more than 70 participants.

\section{Discussion}

The Southeast Raleigh Community Garden Project and Project FACT were both supported by small grants which were written by a volunteer church member. The projects were not conceived as formal research studies but as small-scale public health projects to demonstrate the feasibility of partnering with faith-based organizations to establish a community garden, provide nutritional education and increase opportunities for physical activity. The projects show that it is possible to design programs to improve fruit and vegetable consumption and increase physical activity in a low-income minority population using a community garden as the centerpiece of the project. Even with a shoestring budget, the projects were able to achieve their objectives, including constructing a garden and walking trail, delivering education on healthier eating and providing opportunities for physical activity through the garden, walking 
trail and walking programs. The projects resulted in substantial physical changes in the community that encouraged improvements in nutrition and physical activity habits. The community garden beautified the local area, and produced fresh and nutritious foods while providing valuable recreational, spiritual and therapeutic opportunities and resources. The gardening program was well-received by participants who expressed satisfaction with the program and their intention to increase fruit and vegetable intake and increase physical activity when they were interviewed about their family's experience with the garden. The program also led to policy changes for the child care center, school, church related activities and community food assistance program.

The community garden is highlighted in a publication and DVD produced by the Cooperative Extension at North Carolina A\&T State University as a model of a successful urban horticulture program which demonstrated the feasibility of increasing healthy food production and consumption and physical activity. The results of the community garden pilot project are consistent with the World Commission on Environment and Development (WCED)'s report that urban food growing allows greater access to food for the urban poor, supports urban development and has the economic benefit of additional income from surpluses (WCED, 1987). The project provides preliminary information about the acceptability of programs led by faith-based organizations to increase fruit and vegetables consumption through community gardening.

Both the community garden and Project FACT promote healthy behaviors consistent with the 2005 Dietary Guidelines including increased dietary intake of fruits and vegetables and more frequent physical activity. These projects are an example of a strategy that may help to narrow the disparity that exists between African Americans and non-Hispanic Whites in relation to diet-related chronic health conditions including overweight and obesity, heart disease, stroke, cancer and diabetes. Building on the socio-ecological approach, the community garden initiative provided the framework for the individual, the family and the community to influence positive lifestyle habits by engaging in increased levels of physical activity, learning about gardening and making changes to healthier eating habits (Kretzmann \& McKnight, 1993). The changes observed within the church community and surrounding neighborhood are consistent with the reported benefits of community gardening including increased social interaction, beautification of the neighborhood, production of nutritious food, reduction in family food costs and increased opportunities for recreation, physical activity and education (American Community Gardening Association, 2007).

Project FACT, a complement to the community garden, provides further evidence that a faithbased initiative can be implemented using volunteers to make changes in the community. This project achieved its major goals of increasing physical activity opportunities for church members and youth and families from the nearby neighborhoods, providing educational programs highlighting the benefits of physical activity and healthy eating habits, and implementing walking programs for church and community members. The walking programs also led to a petition that has been approved by the City of Raleigh to construct a sidewalk in the community. A sidewalk to connect the church, playground and the garden with a local park and surrounding neighborhoods will result in enhanced access to physical activity opportunities at the local park and on the church property. This is noteworthy because the addition of the sidewalk is a permanent change that provides a safe walking route and can help sustain walking for physical activity among nearby residents.

\section{Limitations}

Despite the overall success of the community garden and Project FACT, the projects experienced some challenges. A drought in 2007 led to water restrictions that consequently lessened the output of the garden during the final year of the pilot grant. The entrepreneurial aspect of the garden was limited because of the 
expense of permits required by the city to operate food-related businesses, including roadside market stands.

Beyond the logistical challenges, the projects were limited by the lack of resources to quantitatively evaluate their impact. There was little opportunity to formally evaluate the projects because there was no paid staff to collect data to rigorously measure diet and physical activity before, during and after the programs. There were numerous indicators of the success of the projects including the considerable volume of produce from the garden, the changes in church policies regarding food served at the school, day care center and church events, and the participation by more than 300 individuals in the educational, gardening and walking programs. However, the lack of formal evaluation procedures precluded the determination of the effects of the programs on physical activity, dietary habits and obesity. Being able to demonstrate quantitatively the benefits in these areas would provide a stronger basis for promoting community garden interventions in other settings.

Another limitation is the generalizability of the results. Youth and their families who participated in the project might differ from the general population, from individuals who do not attend church, and from individuals who chose not to volunteer in faith-based related projects. The individuals who decide to participate in a faith-based health promotion project may already have a stronger connection to their community and may be more motivated to take part in activities that contribute to the betterment of the neighborhood.

\section{Future Directions}

Based on the outcomes of these projects it is recommended that: 1) the feasibility of community gardens be evaluated within a larger sample of African American youth and families,

2) qualitative and quantitative evaluations should be completed during the implementation of faith-based community programs to determine their impact on dietary patterns, physical activity and obesity among African American youth and families, and 3) additional projects be conducted to demonstrate the feasibility of community gardens in settings other than a faith-based community.

Faith-based health promotion projects such as the community garden and Project FACT demonstrate the feasibility of using partnerships between faith-based organizations, government agencies and community residents to build a foundation for healthy and sustainable habits by providing an environment where youth, their families and other community residents can engage in physical activity and improve nutrition to combat obesity in communities in low socioeconomic areas. Community gardens have the potential to empower residents to take on more active roles in the development of their neighborhoods (Jamison, 1985: Linn, 1999).

\section{Summary}

The overall purpose of the two faith-based health promotion projects was to reduce the proportion of youth and adults who engaged in no leisure-time physical activity and increase the number of youth and adults who eat at least five servings of fruits and vegetables per day. The faith-based partnership implemented several programs to work towards these goals. The Southeast Raleigh Community Garden project successfully created a garden, delivered educational programs to increase children's awareness of the variety of fresh fruits and vegetables produced and initiated policy changes to encourage consumption of healthier foods at the day care center, school and church events. Project FACT expanded the nutritional educational activities to members of other churches and community members and implemented programs to increase physical activity opportunities.

These results provide descriptive information about the feasibility of working with African American churches to implement health promotion programs and contribute to our understanding of the potential impact of faithbased programs when addressing the complex issues surrounding nutrition and physical activity behaviors. This work adds to the existing literature on methods for increasing physical activity levels in African American 
communities and provides preliminary information about the potential for a faith-based program to increase physical activity levels among sedentary African American adults and children (Whitt-Glover, Hogan, Lang \& Heil, 2008). Larger studies with more representative samples are needed to confirm these findings and inform future interventions. Future research also should determine the impact of faith-based programs compared with a control group (WhittGlover, Hogan, Lang, \& Heil, 2008).

Our results suggest many barriers to improving nutrition and physical activities are changeable with policy and environmental interventions. Our projects give testament to a statement written by Reverend Dr. Melvin B. Tuggle, II of Garden of Prayer Baptist Church in Baltimore, MD: "For every problem that exists in the African American community, one can find the solution at the church ... So, look at the church as a unit of social support and a program and education site" (Tuggle, 1995). Other community-based collaborations can learn from our experiences.

\section{Acknowledgments}

The North Carolina A \& $\mathrm{T}$ Cooperative Extension Innovation Program Grant funded the Southeast Raleigh Community Garden pilot project. Project FACT was funded by the John Rex Endowment, Active Community and Neighborhood grants through the Physical Activity and Nutrition Branch located in the NC Division of Public Health. The John Rex Endowment has contributed an initial \$2.5 million to support Healthy Weight Initiative grants as part of a long-term commitment to combating childhood obesity. The authors wish to thank the community gardening team, community partners, and participating community members for their contributions to this project. The authors had no professional relationship with any company or manufacturer that would benefit from the results of this project.

\section{References}

American Community Gardening Association (2007). The Community Gardener. Available at: http://public.gripserver4.com/garden/html/docs/newsletters/ACGA\%20NewsletterSpring07final.p df.

Bopp M, Lattimore D, Wilcox S, Laken M, McClorin L, et al. (2007) Understanding physical activity participation in members of an African American church: a qualitative study. Health Education Resources, 22(6):815-26.

Campbell MK, Demark-Wahnefried W, Symons M, Kalsbeek WD, Dodds J, Cowan A, et al. (1999) Fruit and vegetables consumption and prevention of cancer: the Black Churches United for Better Health Project. American Journal of Public Health, 89(9):1390-6.

Campbell MK, Motsinger BM, Ingram A, Jewll D, Makarushka C, Beatty B, et al. (2000) The North Carolina Black Churches United for Better Health Project: intervention and process evaluation. Health Education Behavior, 27(2):241-53.

Centers for Disease Control and Prevention (CDC) (2009). 5 A Day. Available at: http://www.5aday.gov/. Accessed February 4, 2009

Crespo, C.J. (2005). Physical activity in minority populations: Overcoming a public health challenge. President's Council on Physical Fitness and Sports Research Digest, Series 6, No.2.

Davies, K. (1998, December 18). Penjing: An ancient art with a modern T\twist. Gardening Techniques, 4.

Doshi NJ, Hurley RS, Garrison ME, Stombaugh IS, Rebovich EJ, Wodarski LA, et al. (1994) Effectiveness of a nutrition education and physical fitness training program in lowering lipid levels in the black elderly. Journal of Nutrition Elder, 13(3):23-33. 
Warren-White,N., Moorman,P., Dunn,M.J., Mitchell,C.S., Fisher,A., \& Floyd, M.F./ Californian Journal of Health Promotion 2009,

Dunn, C., Thomas, C., Pegram, L., \& Schmal, S. (2004) Color Me Healthy, preschoolers moving and eating healthfully. Journal of Nutrition Education and Behavior, 36(6), 327-328.

Eight Weeks to Wellness (2009). Available at: http://www.8ww.com/. Accessed February 4, 2009.

Fitness for Life (2009). Available at: http://www.wellsource.org/product_sheets/FFL.pdf. Accessed February 4, 2009.

Freedman, D.S. \& Mei, Z., Srinivasan, S.R., Berenson, G.S., \& Dietz, W.H. (2007). Cardiovascular risk factors and excess adiposity among overweight children and adolescents. The Bogalusa Heart Study. Journal of Pediatrics, 150(1), 12-17.

Heinrich KM, Lee RE, Suminski RR, Reagan GR, Reese-Smith JY, et al. (2007) Associations between the built environment and physical activity in public housing residents. International Journal Behavior of Nutrition and Physical Activity,4,56.

Jamison, M.S. (1985). The joys of gardening: Collectivist and bureaucratic cultures in conflict. The Sociological Quarterly, 26(4), 473-490.

Jones D.A., Ainsworth, B.E., Crofi, J.B., Macera, C.A., Lloyd, E.E., \& Yusuf, H.R. (1998). Moderate leisure-time physical activity: who is meeting the public health recommendations? A national cross-sectional study. Archives of Family Medicine, 7, 285-9.

Klick, R. Ten tips on Gardening with Kids. American Community Gardening Association. Available at: http://www.communitygarden.org/learn/best-practices-10-tips-series.php. Accessed February 4, 2009.

Garden Mosaics (2009). Available at: http://www.gardenmosaics.cornell.edu/. Accessed February 4, 2009.

Kretzmann J., McKnight J. Building Communities from the Inside Out: A Path Toward Finding and Mobilizing a Community's Assets. Evanston, IL: Institute for Policy Research, 1993.

Kumanyika, S.K. \& Charleston, J.B. (1992). Lose weight and win: a church-based weight loss program for blood pressure control among black women. Patient Education and Counseling, 19(1), 19032.

Lasater, T.M., Becker, D.M., Hill, M.N., \& Gans, K. (1997). Synthesis of findings and issue from religious-based cardiovascular disease prevention trials. Annual Epidemiology, S7, S46-53.

Lasater, T.M., Wells, B.L., Carleton, R.A., \& Elder, J.P. (1996). The role of churches in disease prevention research studies. Public Health Reports, 101(2),125-31.

Linn, K. (1999). Reclaiming the sacred commons. New Village, 1(1),42-49.

National Gardening Association. Available at:_http://www.kidsgardening.com/._Accessed February 4, 2009.

North Carolina A\&T State University Cooperative Extension Program (2009). Down to Earth. Available at:_http://www.ag.ncat.edu/extension/programs/dte/index2.html. Accessed February 4, 2009.

Ogden, C.L., Caroll, M.D., Curtin, L.R., McDowell, M.A., Tabak, C.J. Flegal, K.M. (2006). Prevalence of overweight and obesity in the United States, 1999-2004. JAMA, 295(13), 1549-1555.

Olson, L.M., Reis, J., Murphy, L., \& Gehm, J.H. (1988). The religious community as a partner in health care. Journal of Community Health, 13(4), 249-57.

Oexmann MJ, Thomas JC, Taylor KB, O’Neil PM, Garvey WT, Lackland DT, et al. (2000) Short-term impact of a church-based approach to lifestyle change on cardiovascular risk in African Americans. Ethnic Disorders, 10(1):17-23.

Pan, L., Galuska, D.A., Sherry, B., Hunter, A.S., Rutledge, G.E., Dietz, W.H. (2009). Difference in Prevalence of Obesity Among Black, White, and Hispanic Adults- United States, 2006-2008. Morbity and Mortality Weekly Report. 58(27);740-744.

Physical Activity and Nutrition Branch (2004). African American Churches Eating Smart and Moving Move: A Planning and Resource Guide. NC DHHS, NC Division of Public Health, Raleigh, NC.

Resnicow K, Jackson A, Braithwaite R, Dilorio C, Blisset D, Rahotep S, et al. (2002) Healthy Body/Healthy Spirit: a church-based nutrition and physical activity intervention. Health Education Resources, 17(5):562-73. 
Resnicow, K., Campbell, M.K., Carr, C. McCarty, F., Wang, T., Periasamy, S., Rahotep, S., Doyle, C., Williams, A. \& Stables, G. (2004). Body and Soul: A dietary intervention conducted through African American churches. American Journal of Preventive Medicine 27(2),97-105.

Serdula MK, Ivery D, Coates RJ, Freedman DS. Williamson DF. Byers T. Do obese children become obese adults? A review of the literature. Preventative Medicine 1993;22:167-177.

Smith ED, Merritt SL, Patel MK. (1997) Church-based education: an outreach program for African Americans with hypertension. Ethnic Health, 2(3):243-53.

Tuggle, MB. New Insights and Challenges about Churches as Intervention Site to Reach the AfricanAmerican Community with Health Information. Journal of the National Medical Association. 1995;87:supp.

US Department of Health \& Human Services (USDHHS). (1996). Physical activity and health: a report of the Surgeon General. Hyattsville MD: USDHHS, Center of Disease Control and Prevention (CDC).

Voorhees CC, Stilman FA, Swank RT, Heagerty PJ, Levine DM, Becker DM. (1996) Heart, body, and soul: impact of church-based smoking cessation interventions on readiness to quit. Preventative Medicine, 25(3):277-85.

Whitaker, R.C., Wright, J.A., Pepe, M.S., Seidel, K.D., \& Dietz ,W.H. (1997). Predicting obesity in young adulthood from childhood and parental obesity. New England Journal of Medicine, 37(13),869-873.

Whitt-Glover, M., Hogan, P., Lang, W., \& Heil, D. (2008). Pilot Study of a faith-based physical activity program among sedentary blacks. Preventing Chronic Disease, 5(2).

Wiist WH, Flack JM. (1990) A church-based cholesterol education program. Public Health Report, 105(4):381-8.

World Commission on Environment and Development (1987). Our Common Future. New York: Oxford University Press.

Yanek LR, Becker DM, Moy TF, Gittelson J, Koffman DM. (2001) Project Joy: faith based cardiovascular health promotion for African American women. Public Health Report, 116(Suppl 1):68-81.

Zenk SN, Wilbur J, Wang E, McDevitt J, Oh A et al. (2009) Neighborhood environment and adherence to a walking intervention in African American women. Heath Education Behavior. 36(1):167-81.

\author{
Author Information \\ *Nicolette Warren, M.S. RHEd, CHES \\ Society for Public Health Education \\ 10 G Street, NE, Suite 605 \\ Washington, DC 20002 \\ Email: nwarren@sophe.org \\ Telephone: 202-408-9804 \\ Fax: 202-408-9815 \\ Patricia Moorman $\mathrm{PhD}$ \\ Department of Community and Family Medicine, \\ Duke University Medical Center \\ Morris J. Dunn \\ NC Cooperative Extension, Wake County Center \\ Carol S. Mitchell PhD, RD, LDN \\ NC Cooperative Extension, Wake County Center
}


Warren-White,N., Moorman,P., Dunn,M.J., Mitchell,C.S., Fisher,A., \& Floyd, M.F./ Californian Journal of Health Promotion 2009, Volume 7,Special Issue (Obesity Prevention), 87- 98

Ariel Fisher

Gethsemane Seventh-day Adventist Church

Myron F. Floyd PhD

Department of Parks, Recreation and Tourism Management

College of Natural Resources

North Carolina State University

* corresponding author 